\title{
Tranexamic Acid Utilization in Craniosynostosis Surgery
}

\author{
Ebru Atike ONGUN ${ }^{1}$, Oguz DURSUN ${ }^{1}$, Mehmet Saim KAZAN² \\ ${ }^{1}$ Akdeniz University Faculty of Medicine, Department of Pediatrics, Division of Pediatric Critical Care, Antalya, Turkey \\ ${ }^{2}$ Akdeniz University Faculty of Medicine, Department of Neurosurgery, Antalya, Turkey \\ This study has been presented as an oral presentation at $22^{\text {nd }}$ International Intensive Care Symposium between 3 and 4 May 2019 at Istanbul, Turkey.
}

Corresponding author: Ebru Atike ONGUN ebruongun@akdeniz.edu.tr

\section{ABSTRACT}

AIM: To analyze the impact of Tranexamic acid (TXA) on perioperative hemodynamics in craniosynostosis surgery.

MATERIAL and METHODS: Data of thirty-six children (operated between 2014-2017) were categorized into two groups depending on TXA delivery. Patient demographics, preoperative, intraoperative, postoperative data on hemostasis and metabolic outcomes were recorded. Blood loss from the drains, estimated blood loss (EBV loss), volume of blood transfusions, hemodynamic alerations and complications were extracted. Postoperative outcome involved variables at admission, $2^{\text {nd }}, 6^{\text {th }}, 12^{\text {th }}, 24^{\text {th }}$ hours. A multiple logistic regression analysis was also performed.

RESULTS: Demographics presented mean age of $8.14 \pm 3.53$ months, male/female ratio:1.76/1, procedure length $3.98 \pm 0.78$ hours. Intraoperative analysis indicated TXA deliveries manifested fewer blood transfusion volumes ( $p=0.002)$ due to lower EBV loss $(4.02 \pm 1.19 \mathrm{ml} / \mathrm{kg}$ vs. $5.97 \pm 1.61 \mathrm{ml} / \mathrm{kg}, \mathrm{p}<0.001)$ with better metabolic outcome.

Postoperative outcomes presented all children manifested hematocrit decline after surgey. TXA did not influence postoperative hemodynamic alterations $(p=0.090, p=0.112)$, despite reduced blood loss from the drains and transfusion necessity $(p=0.015$, $\mathrm{p}=0.0175)$. Intraoperative transfusion volumes and EBV loss were associated with postoperative hemodynamics (OR: $3.033,95 \% \mathrm{Cl}$ : 1.286-7.154; $p=0.011$; OR: $0.280,95 \% \mathrm{Cl}: 0.081-0.972 ; \mathrm{p}=0.045$, respectively). ROC analysis indicated $10.13 \mathrm{ml} / \mathrm{kg}$ of intraoperative blood transfusion requirement as the cut off value for hemodynamic instability with $91 \%$ sensitivity and $80 \%$ specificity. One unit increase in intraoperative transfused blood volume increased the odds of developing hemodynamic alterations by 3.033 times.

CONCLUSION: Intraoperative TXA is crucial for successful surgical management; however postoperative period carries out paramount importance due to excessive bleeding after surgery. In case of severe intraoperative transfusion necessity, postoperative TXA utilization might be considered to minimize potential risks by balancing the pros and cons of the drug.

KEYWORDS: Tranexamic acid, Craniosynostosis, Blood loss, Surgery

ABBREVIATIONS: TXA: Tranexamic acid, Hct: Hematocrit, EBV loss: Estimated blood volume loss, FFP: Freshfrozenplasma, PLT: Platelet, INR: International normalized ratio, Hb: Hemoglobin, LOS: Length of stay, HCO3: Bicarbonate, BE: Base excess, pRBC: Packed red blood cell, PICU: Pediatric intensive care unit.

\section{INTRODUCTION}

C raniosynostosis is premature fusion of the cranial sutures and may lead to a cranial growth restriction if no intervention occurs (3). Surgical intervention is the treatment of choice; however, it embodies substantial risks of perioperative bleeding due to the enriched capillary network of the skull (29). Frequent perioperative transfusions also contribute to the odds of developing complications, such as transfusion-related acute lung injury, acute hemolytic reaction, blood contamination, or circulatory overload due to transfusion volume (16). 
Blood management protocols have been implemented to reduce transfusion requirements for cranial vault surgery. Erythropoietin alpha (EPO) and intravenous iron administration prior to surgery (25), intraoperative blood salvage (18), autologous bank donations (20), acute normovolemic hemodilution (12), and lower hemoglobin thresholds for the transfusion requirement have been implemented in recent years (34). The use of tranexamic acid (TXA) as an antifibrinolytic drug to reduce perioperative bleeding has gained popularity and is used during various procedures $(3,9,27,29)$. TXA is a synthetic analog of lysine that acts on plasminogen molecules by blocking lysine binding sites; hence, it inhibits the conversion of plasminogen to plasmin (21). Studies regarding the use of TXA during craniosynostosis surgery mostly involve intraoperative blood loss. However, postoperative outcomes are equally important in small children because of their relatively large head circumference to body mass and significant volume of blood loss by oozing from the skull surface $(14,29)$.

Craniosynostosis surgery is performed regularly on infants at referral university hospitals in the Mediterranean region. To maintain hemostasis during the perioperative period, our institutional policy has included the administration of TXA during cranial vault surgery since August 2015. Therefore, we planned a retrospective study to analyze the efficacy of TXA administration for perioperative hemodynamic outcomes in children undergoing craniosynostosis surgery.

\section{MATERIAL and METHODS}

We obtained approval from the local ethics committee (code: 2012-KAEK-20; no: 427, date: 27.06.2018). Thirty-nine synostotic children operated on at Akdeniz University Hospital between January 2014 and January 2018 were included in this study. The senior author (MSK) performed the procedures using open surgical techniques. Three patients were excluded from the study due to a lack of intraoperative data. Thirty-six children were categorized into two groups, based on whether they received TXA.

The institutional blood management protocol includes TXA at a loading dose of $50 \mathrm{mg} / \mathrm{kg}$ followed by a $5 \mathrm{mg} / \mathrm{kg}$ per hour infusion throughout the procedure. Intraoperative transfusion requirements depend on the transfusion guidelines $(17,30,31)$ : blood pressure drops with hematocrit (Hct) $<30 \%$, acute bleeding resulting in a $15 \%$ estimated blood volume loss (EBVloss) during surgery, tachycardia and any clinical signs of acute anemia in the presence of Hct $<24 \%$. However, the postoperative transfusion threshold was set to hemoglobin $<8 \mathrm{~g} / \mathrm{dL}$ in the absence of hemodynamic instability. Fresh frozen plasma (FFP) and platelet (PLT) transfusions were also recorded (in case of clinical coagulopathy, such as PLT $<50,000 \mathrm{~mm}^{3}$ or international normalized ratio $>2$ times the reference value).

Patient demographics (age, sex, diagnosis, type of procedure), preoperational hemoglobin $(\mathrm{Hb})$ and $\mathrm{Hct}$, and length of the surgery were recorded. The intraoperative analysis included the lowest obtained values for repeated measures during the procedure, including intraoperative $\mathrm{Hb}$, Hct (\%), blood gas $\mathrm{pH}$, bicarbonate $\left(\mathrm{HCO}_{3}\right)$ and base excess $(\mathrm{BE})$. The decline in Hct during the procedure was calculated by subtracting the lowest Hct measured during surgery from the preoperative Hct value. If given, we recorded intraoperative volume of packed red blood cell (pRBC), FFP, and PLT infusions as well as any observed hemodynamic alterations and complications during the procedure.

Postoperative outcome involved the first 24 hours in the pediatric intensive care unit (PICU). Time repeated variables at admission and at 2, 6, 12, and 24 hours were analyzed. We also documented blood gas parameters $\left(\mathrm{pH}, \mathrm{HCO}_{3}\right.$ and $\mathrm{BE})$ at admission and at 2, 6, and 12 hours. Blood loss from the drains ( $\mathrm{ml} /$ day) was recorded. To determine the blood loss accurately, we calculated weight-adjusted EBVloss during the procedure and during the postoperative period by adapting a previous formula $(9,33)$ :

$\left.\mathrm{EBV}_{\text {loss }}(\mathrm{ml} / \mathrm{kg})=\mathrm{ERCV}_{\text {lost }} \mathrm{ml}\right) /$ weight $(\mathrm{kg}) \times$ hematocrit preop $/ 100$;

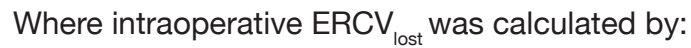

$\mathrm{ERCV}_{\text {preop }}+\mathrm{ERCV}_{\text {transfused }}-\mathrm{ERCV}_{\text {intraop}}$.

ERCV (estimated red cell volume) = estimated blood volume $(\mathrm{EBV}) \times$ hematocrit/100

*Estimated blood volume was $80 \mathrm{ml} / \mathrm{kg}$ and $75 \mathrm{ml} / \mathrm{kg}$ for infants younger and older than 12 months, respectively.

${ }^{*}$ To calculate postoperative EBV ${ }_{\text {loss }}(\mathrm{ml} / \mathrm{kg})$ : we adapted a previous formula by replacing intraoperative Hct and ERCV to the preoperative values; and postoperative Hct and $E R C V$ to the intraoperative values.

All intubated patients were transferred directly to the PICU from the operating room. Once hemodynamic balance was achieved, sedation weaning and extubation were initiated. The length of intubation and the lengths of the PICU and hospital stays were all recorded for analysis. Any surgery or drug-related complication (seizure, thrombosis, hemorrhage, or hemodynamic instability) and postoperative computed tomography (CT) scans were examined until hospital discharge.

SPSS version 23 software (SPSS Inc., Chicago, IL, USA) was used for the statistical analysis. Descriptive analyses are presented as frequency $(\mathrm{n})$, percentage (\%), mean \pm standard deviation, and median (range) values. Categorical data were assessed using the $\mathrm{x} 2$ and Fisher exact test; continuous variables were analyzed by Mann-Whitney $U$-test or the independent samples $t$-test. Repeatedly measured variables, such as $\mathrm{Hb}$, Hct, blood gas $\mathrm{pH}, \mathrm{HCO}_{3}$, and $\mathrm{BE}$ were analyzed using Bonferroni corrected linear mixed models. Multiple logistic regression models were applied to analyze the risk factors for hemodynamic instability. A p-value $<0.05$ was considered significant. 


\section{RESULTS}

Thirty-six infants (mean age $8.14 \pm 3.53$ months and weight $8.14 \pm 2.14 \mathrm{~kg}$ ) were included in the study at a male/female ratio of $1.76: 1$. Trigonocephaly was the common diagnosis $(47.2 \%)$ and the mean procedure length was $3.98 \pm 0.78$ hours. The groups did not present any differences in terms of age, weight, sex, or length of hospital stay $(p=0.257, p=0.462$, $\mathrm{p}=0.923, \mathrm{p}=0.935$, respectively). The preoperative data also revealed similar Hct values between the groups (TXA: $33.92 \%$ $\pm 2.23 \%$, non-TXA: $34.27 \% \pm 2.39 \% ; p=0.653$ ). Table I shows the demographics of the population.

The intraoperative analysis indicated that all children received pRBC transfusions throughout the procedure due to drops in Hct following the incision; however, TXA manifested lower blood transfusion volumes $(p=0.002)$ due to lower weightadjusted EBVloss $(4.02 \pm 1.19 \mathrm{ml} / \mathrm{kg}$ vs. $5.97 \pm 1.61 \mathrm{ml} / \mathrm{kg}$, $\mathrm{p}<0.001$; Figure 1). The metabolic parameters also favored the use of TXA at higher $\mathrm{pH}$ and $\mathrm{HCO}_{3}$ levels $(\mathrm{p}=0.005$ for $\mathrm{pH} ; \mathrm{p}=0.008$ for $\mathrm{HCO}_{3} ; \mathrm{p}<0.001$ for $\mathrm{BE}$ ). Table II presents the intraoperative hematological and metabolic outcomes in both groups. No drug or surgery-related complications, including hemodynamic alterations, were noted throughout the surgery.

The postoperative outcomes at different time intervals are presented at Tables II and III. Regardless of drug administration, all children manifested a decline in Hct at the early follow up $(p=0.091$, Table III, Figure 2$)$, yet TXA influenced the postoperative outcomes in terms of reduced blood loss volumes from the drains and pRBC transfusions $(p=0.015, p=0.0175)$. We observed a linear correlation between intraoperative blood transfusion volume and the postoperative transfusion requirement (greater intraoperative transfusion volume, more frequent postoperative transfusion necessity; $p=0.015)$. However the metabolic outcomes for

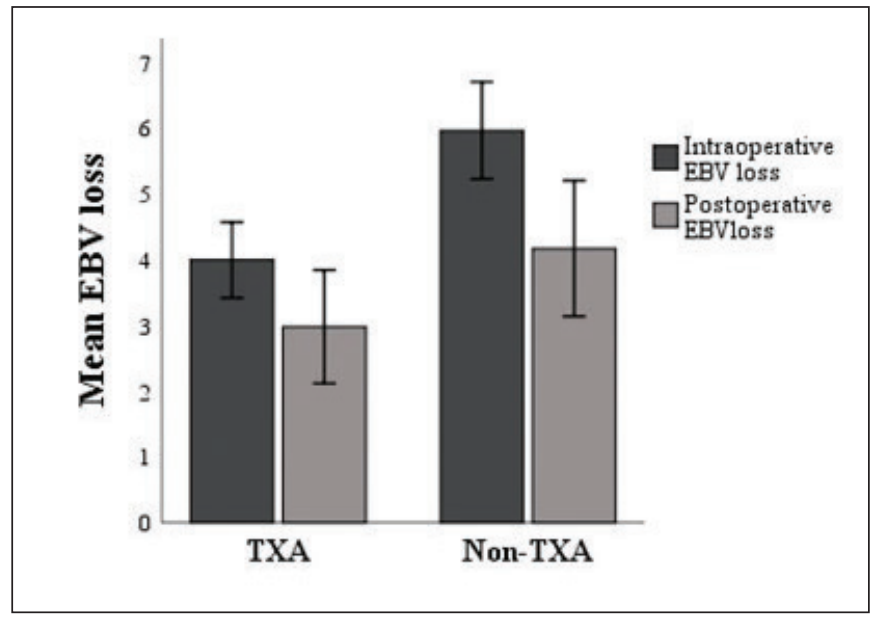

Figure 1: Intraoperative and postoperative EBV loss.

Table I: The Demographics of the Study Population

\begin{tabular}{|c|c|c|c|}
\hline & $\begin{array}{l}\text { TXA group } \\
\quad(n=17)\end{array}$ & $\begin{array}{l}\text { Non-TXA group } \\
(n=19)\end{array}$ & $\mathbf{p}$ \\
\hline Age, (mean \pm SD) & $8.85 \pm 3.78$ & $7.5 \pm 3.25$ & 0.257 \\
\hline Weight, (mean \pm SD) & $8.42 \pm 2.31$ & $7.89 \pm 2.01$ & 0.462 \\
\hline \multicolumn{4}{|l|}{ Gender, n (\%) } \\
\hline $\begin{array}{l}\text { Female } \\
\text { Male }\end{array}$ & $\begin{array}{r}6(35.3) \\
11(64.7)\end{array}$ & $\begin{array}{r}7(36.8) \\
12(63.2)\end{array}$ & 0.923 \\
\hline \multicolumn{3}{|l|}{ Craniosynostosis, $\mathbf{n}(\%)$} & \multirow{5}{*}{ NA } \\
\hline Trigonocephaly & $9(52.9)$ & $8(42.1)$ & \\
\hline Scaphocephaly & $7(41.2)$ & $7(36.8)$ & \\
\hline Brachiocephaly & $1(5.9)$ & $1(5.3)$ & \\
\hline Anterior plagiocephaly & - & $3(15.8)$ & \\
\hline \multicolumn{3}{|l|}{ Operation Type, n (\%) } & \multirow{4}{*}{ NA } \\
\hline Total calvarial reconstruction & $7(41.2)$ & $7(36.8)$ & \\
\hline Frontoorbital advancement & $7(41.2)$ & $8(42.1)$ & \\
\hline Strip craniectomy & $3(17.6)$ & $4(21.1)$ & \\
\hline Length of surgery, (hours), median (min-max) & $4(3-5.5)$ & $4(3-6)$ & 0.935 \\
\hline Length of intubation (hours), median (min-max) & $6(3-16)$ & $5(1-15)$ & 0.584 \\
\hline Length of PICU stay, (days) median (min-max) & $2(2-3)$ & $3(1-6)$ & 0.155 \\
\hline Length of hospitalization, (days) (mean \pm SD) & $9.71 \pm 1.31$ & $11.79 \pm 1.55$ & $<0.001$ \\
\hline
\end{tabular}


Table II: Hematological and Metabolic Outcome

\begin{tabular}{|c|c|c|c|}
\hline & $\begin{array}{l}\text { TXA group } \\
(n=17)\end{array}$ & $\begin{array}{l}\text { non-TXA group } \\
\qquad(n=19)\end{array}$ & $\mathbf{p}$ \\
\hline \multicolumn{4}{|l|}{ Preoperative Period } \\
\hline Hematocrit $(\%)$ (mean \pm SD) & $33.92 \pm 2.23$ & $34.27 \pm 2.39$ & 0.653 \\
\hline Hemoglobin, (gr/dL) (mean \pm SD) & $11.41 \pm 0.68$ & $11.39 \pm 1.07$ & 0.942 \\
\hline Hematocrit $(\%),($ mean \pm SD) & $27,26 \pm 3,39$ & $24,37 \pm 2,57$ & 0.007 \\
\hline Hemoglobin, $(\mathrm{gr} / \mathrm{dL})($ mean $\pm \mathrm{SD})$ & $8,96 \pm 0,8$ & $8,14 \pm 0,93$ & 0.008 \\
\hline Hematocritdecline, (mean \pm SD) & $-6.66 \pm 3.69$ & $-9.89 \pm 2.27$ & 0.003 \\
\hline Hemoglobin decline, (mean \pm SD) & $-2.45 \pm 0.65$ & $-3.25 \pm 0.71$ & 0.001 \\
\hline Transfused pRBC volume* & $9.02 \pm 3.08$ & $11.55 \pm 4.63$ & 0.002 \\
\hline FFP transfusion n (\%) & $2(11.8)$ & $3(15.8)$ & NA \\
\hline \multicolumn{4}{|l|}{ Blood gas parameters } \\
\hline $\mathrm{pH}^{*}$ & $7.35(7.25-7.45)$ & $7.33(7.19-7.40)$ & 0.005 \\
\hline $\mathrm{HCO}_{3}(\mathrm{meq} / \mathrm{L})^{*}$ & $16.4(13-24)$ & $15(10-26)$ & 0.008 \\
\hline $\mathrm{BE},($ mean $\pm \mathrm{SD})$ & $-6.78 \pm 2.14$ & $-9.54 \pm 1.52$ & $<0.001$ \\
\hline Lactate $(\mathrm{mmol} / \mathrm{L})^{*}$ & $1.34(0.4-2)$ & $1.36(0.9-3.5)$ & 0.255 \\
\hline \multicolumn{4}{|l|}{ Postoperative Period } \\
\hline
\end{tabular}

*median(min-max).

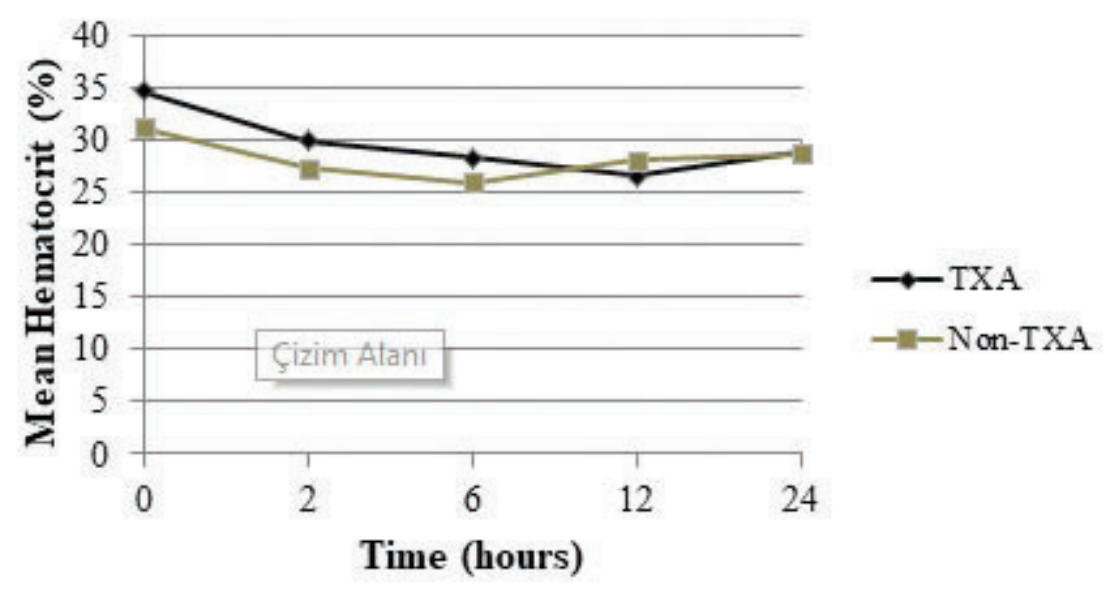

Figure 2: Postoperative time-repeated measures of hematocrit. 
Table III: Postoperative Time-Repeated Outcome

\begin{tabular}{|c|c|c|c|c|}
\hline Parameters & Time (hour) & $\begin{array}{l}\text { TXA group } \\
\quad(n=17)\end{array}$ & $\begin{array}{l}\text { Non-TXA group } \\
(n=19)\end{array}$ & $\mathbf{p}^{*}$ \\
\hline \multirow{6}{*}{$\begin{array}{l}\text { Hematocrit, } \\
(\%) \text { (mean } \pm \text { SD) }\end{array}$} & 0 & $34.14 \pm 4.35$ & $31.85 \pm 5.89$ & 0.199 \\
\hline & 2 & $30.49 \pm 4.40$ & $28.1 \pm 4.12$ & 0.121 \\
\hline & 6 & $28.66 \pm 4.12$ & $26.06 \pm 3.93$ & 0.064 \\
\hline & 12 & $28.02 \pm 4.18$ & $27.82 \pm 4.63$ & 0.894 \\
\hline & 24 & $29.16 \pm 3.18$ & $28.81 \pm 3.20$ & 0.767 \\
\hline & $p^{\star \star}$ & $<0.001$ & 0.051 & 0.091 \\
\hline \multirow{6}{*}{$\begin{array}{l}\text { Hemoglobin, (gr/dL) } \\
\text { (mean } \pm \text { SD) }\end{array}$} & 0 & $11.4 \pm 1.57$ & $10.54 \pm 2.08$ & 0.174 \\
\hline & 2 & $10.12 \pm 1.44$ & $9.39 \pm 1.37$ & 0.148 \\
\hline & 6 & $9.48 \pm 1.48$ & $8.76 \pm 1.3$ & 0.134 \\
\hline & 12 & $9.35 \pm 1.47$ & $9.39 \pm 1.37$ & 0.932 \\
\hline & 24 & $9.76 \pm 1.21$ & $9.44 \pm 1.12$ & 0.457 \\
\hline & $p^{\star *}$ & $<0.001$ & 0.080 & 0.053 \\
\hline \multirow{5}{*}{$\mathrm{Ph},($ mean $\pm \mathrm{SD})$} & 0 & $7.28 \pm 0.06$ & $7.26 \pm 0.07$ & 0.425 \\
\hline & 2 & $7.31 \pm 0.05$ & $7.32 \pm 0.06$ & 0.685 \\
\hline & 6 & $7.35 \pm 0.08$ & $7.35 \pm 0.05$ & 0.999 \\
\hline & 12 & $7.39 \pm 0.03$ & $7.36 \pm 0.06$ & 0.195 \\
\hline & $\mathbf{p}^{\star *}$ & 0.003 & 0.001 & 0.608 \\
\hline \multirow{5}{*}{$\begin{array}{l}\text { HCO3, } \\
(\text { meq/L) }(\text { mean } \pm \text { SD })\end{array}$} & 0 & $18.12 \pm 1.78$ & $16.71 \pm 3.95$ & 0.183 \\
\hline & 2 & $18.31 \pm 1.97$ & $16.81 \pm 3.34$ & 0.128 \\
\hline & 6 & $18.19 \pm 2.14$ & $19.14 \pm 2.69$ & 0.290 \\
\hline & 12 & $20.89 \pm 2.16$ & $20.56 \pm 2.51$ & 0.717 \\
\hline & $\mathbf{p}^{\star \star}$ & $<0.001$ & $<0.001$ & 0.051 \\
\hline \multirow{5}{*}{$\begin{array}{l}\text { BE, } \\
\text { median (min-max) }\end{array}$} & 0 & $-7.9(-10.1--4.7)$ & $-9.3(-14--3.2)$ & 0.098 \\
\hline & 2 & $-6.5(-11.1--3.7)$ & $-7.1(-15--1.6)$ & 0.787 \\
\hline & 6 & $-6(-11--3.5)$ & $-4.4(-9--0.6)$ & 0.065 \\
\hline & 12 & $-2(-6.3-3.7)$ & $-3.2(-7.1--0.1)$ & 0.479 \\
\hline & $p^{\star \star}$ & $<0.001$ & $<0.001$ & 0.041 \\
\hline \multirow{5}{*}{$\begin{array}{l}\text { Lactate } \\
(\mathrm{mmol} / \mathrm{L})(\text { mean } \pm \mathrm{SD})\end{array}$} & 0 & $0.99(0.5-2.9)$ & $1.13(0.5-4.0)$ & 0.749 \\
\hline & 2 & $1.01(0.5-3.1)$ & $1.11(0.5-4.1)$ & 0.533 \\
\hline & 6 & $1.05(0.4-3.9)$ & $0.97(0.1-2.5)$ & 0.620 \\
\hline & 12 & $0.81(0.1-1.8)$ & $0.84(0.5-1.5)$ & 0.870 \\
\hline & $p^{\star *}$ & 0.001 & 0.014 & 0.187 \\
\hline
\end{tabular}

$p^{*}$ defines the significance between TXA and non-TXA groups within a mentioned time period; $p^{* *}$ defines the significance of time-repeated variables of each group. 
blood gas $\mathrm{pH}, \mathrm{HCO}_{3}$, and lactate were not different between the two groups $(p=0.608, p=0.051, p=0.187$ respectively; Table III, Figure 3A-D).

Weaning from the ventilator was initiated in all children as soon as hemodynamic stability was achieved. Eleven children (30.6\%) developed hypotension after the procedure. The administration of TXA had no impact on hemodynamic alterations $(p=0.112$, Table IV). The receiver operating characteristic (ROC) curve analysis for hemodynamic changes indicated the cutoff value for the volume of intraoperative blood transfusion was over $10.13 \mathrm{ml} / \mathrm{kg}$ (area under the curve [AUC]: 0.885, 95\% confidence interval $[\mathrm{Cl}]=0.761-1)$, with sensitivity of $91 \%$ and specificity of $80 \%$. Intraoperative transfusion volumes and EBVloss were associated with postoperative hemodynamics (odds ratio [OR]: $3.033,95 \% \mathrm{Cl}$ : 1.286-7.154; $\mathrm{p}=0.011$ and OR: $0.280,95 \% \mathrm{Cl}: 0.081-0.972$; $p=0.045$, respectively). A 1 unit increase in intraoperative transfused blood volume increased the odds of developing hemodynamic changes by 3.033 times.

The lengths of PICU admission and hospitalization were $2.86 \pm 1.19$ days and $10.81 \pm 1.77$ days, respectively. TXA administration shortened the hospitalization period, but had no effect on PICU stay $(p<0.001, p=0.155)$. Four children (one from the TXA group, three from the non-TXA group) had a superficial hematoma on their cranial CT scans. Seizures were observed in two infants in the TXA group while at the neurosurgical ward; however, attempts to identify the cause were inconclusive because both infants had a previous epilepsy history and were taking anticonvulsive medication before the procedure.

\section{DISCUSSION}

Hemodynamic alterations, metabolic imbalance, and transfusion reactions due to blood loss and blood product transfusions are the major cause of morbidity in patients undergoing cranial vault surgery (32). Blood loss can be 20$500 \%$ of estimated blood volume in the surgical correction and extend beyond the procedure (15). Smaller children often require blood transfusions due to their relatively lower blood volumes (ranging between 50\% and 100\%) (5). Therefore, blood loss and transfusion volume should be minimized to improve patient safety $(16,32)$.

TXA is a commonly used drug for its antifibrinolytic activity in various surgeries $(2-4,9,19,21)$. However little known is about how much of the blot-clotting effect expedites postoperative recovery. Thus, we analyzed both the intraoperative and postoperative data to determine whether TXA contributed to maintaining intensive care hemodynamics. The findings in this study were: TXA successfully reduced blood loss and transfusion volumes during surgery. Intraoperative outcome resembled those documenting an influence of lower blood transfusion volumes and weight-adjusted blood loss $(9,21,29)$.

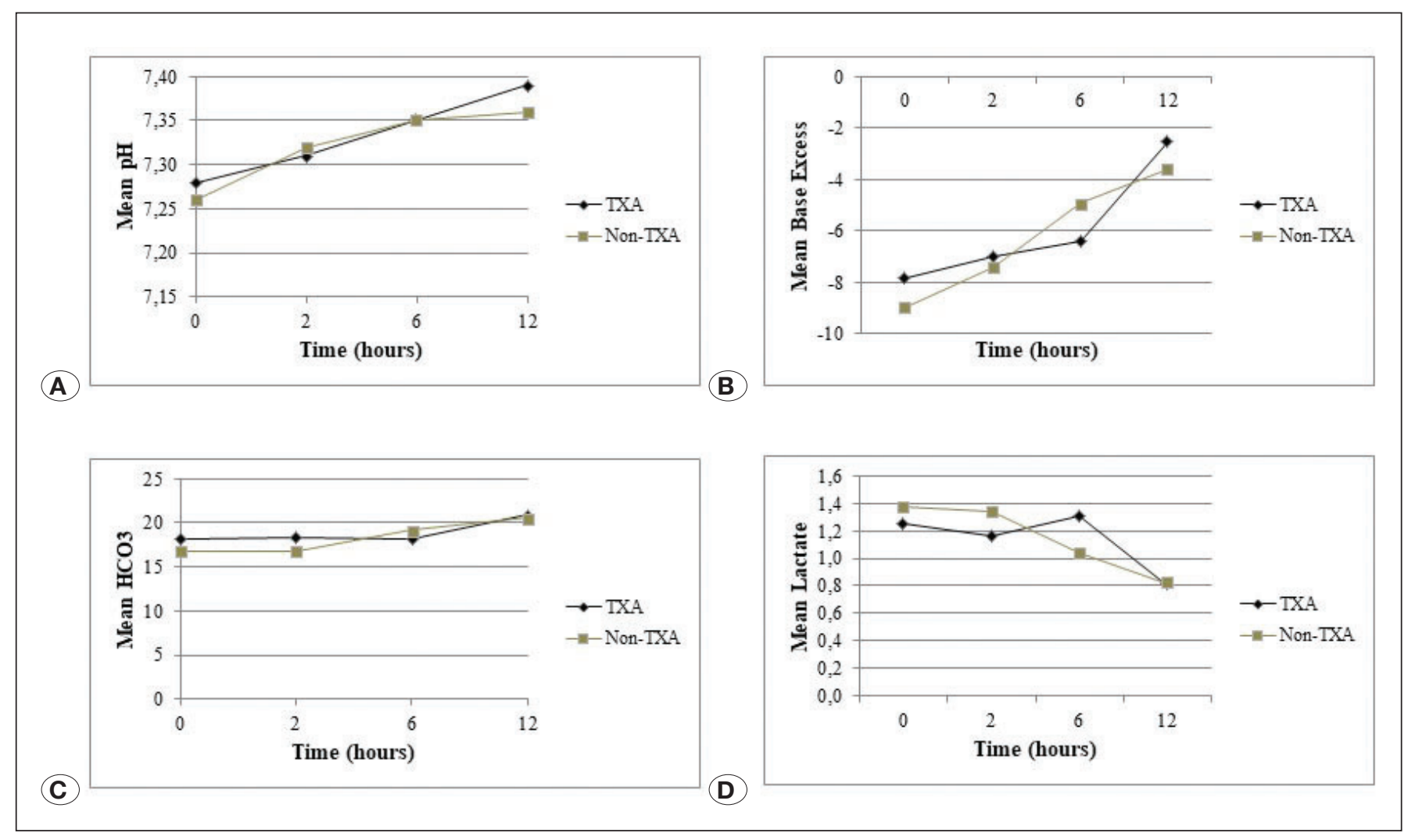

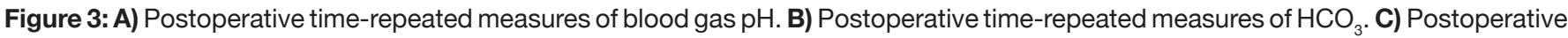
time-repeated measures of base excess (BE). D) Postoperative time-repeated measures of lactate. 
However, the beneficial effect was limited to the postoperative outcome. Even if the postoperative results demonstrated evidence of reduced blood loss from the drains (possibly due to a direct residual effect at the incision site) $(1,9)$, and the need for a transfusion (TXA: $23.5 \%$ vs. non-TXA: $63.2 \%$ ), it was noteworthy to observe the declining Hcts lasting for 12 hours. Kim et al. expressed similar results in the ROTEM study: they also observed reduced transfusion rates, but insignificant volumes of blood loss during the postoperative period (17). The clinical outcomes of both studies were different from other studies reporting less bleeding due to the clot-stabilizing effect from circulating drug levels, which might extend up to 24 hours $(7,9,13)$. The underlying cause of this conflict remains uncertain; it is unknown whether it was because of hemodilution by fluid resuscitation resulting in a $20 \%$ reduction in hemoglobin, oozing of blood from the surgical site $(2,14)$, or excessive bleeding due to the variations in TXA pharmacokinetics $(17,28)$. The young age in the present study population $(8.85 \pm 3.78$ months and $8.14 \pm 2.14 \mathrm{~kg})$ may have altered the drug's pharmacokinetics, as infants $(<1$ year) weighing $<10 \mathrm{~kg}$ exhibit reduced TXA clearance (10).

Table IV: Postoperative Outcome for Hemodynamics

\begin{tabular}{|c|c|c|c|}
\hline & $\begin{array}{l}\text { Hemodynamic } \\
\text { Alteration }(n=11)\end{array}$ & $\begin{array}{l}\text { Intact Hemodynamics } \\
\qquad(n=25)\end{array}$ & $\mathbf{p}$ \\
\hline Age, (months)* & $7.36 \pm 3.14$ & $8.48 \pm 3.7$ & 0.390 \\
\hline Weight, (kg) * & $7.35 \pm 1.49$ & $8.49 \pm 2.32$ & 0.145 \\
\hline \multicolumn{4}{|l|}{ Gender, n(\%) } \\
\hline Male & $6(54.5)$ & $17(68)$ & 0.475 \\
\hline \multicolumn{4}{|l|}{ Craniosynostosis, n(\%) } \\
\hline Trigonocephaly & $5(45.5)$ & $12(48)$ & \multirow{4}{*}{ NA } \\
\hline Scaphocephaly & $3(27.3)$ & $11(44)$ & \\
\hline Brachiocephaly & $1(9.1)$ & $1(4)$ & \\
\hline Anterior plagiocephaly & $2(18.2)$ & $1(4)$ & \\
\hline \multicolumn{4}{|l|}{ Operation type, n(\%) } \\
\hline Total calvarial reconstruction & $6(54.5)$ & $8(32)$ & \multirow{3}{*}{ NA } \\
\hline Frontoorbital advancement & $2(18.2)$ & $13(52)$ & \\
\hline Strip craniectomy & $3(27.3)$ & $4(16)$ & \\
\hline Length of surgery, (hours) ** & $4(3-6)$ & $3.5(3-6)$ & 0.074 \\
\hline TXA administration, $\mathbf{n}(\%)$ & $3(27.3)$ & $14(56)$ & 0.112 \\
\hline Hematocrit Decline * & $-8.64 \pm 2.7$ & $-8.25 \pm 3.71$ & 0.757 \\
\hline Hemoglobin Decline * & $-2.9 \pm 0.76$ & $-2.86 \pm 0.81$ & 0.901 \\
\hline Intraop. transfusion volume, $(\mathrm{ml} / \mathbf{k g})^{\star}$ & $15.86 \pm 3.89$ & $9.46 \pm 3.43$ & $<0.001$ \\
\hline Intraop. EBVloss, (ml/kg)* & $6.01 \pm 1.71$ & $4.61 \pm 1.57$ & 0.022 \\
\hline Postop EBVloss, (ml/kg)* & $3.68 \pm 1.97$ & $3.57 \pm 2.19$ & 0.744 \\
\hline Blood loss from the drains (ml/day)* & $33.18 \pm 16.01$ & $27.2 \pm 12.6$ & 0.236 \\
\hline $\mathrm{HCO}_{3}$ replacement, n (\%) & $11(100)$ & $18(72)$ & 0.076 \\
\hline Postoperative albumin, (gr/dL)* & $3.46 \pm 0.65$ & $3.48 \pm 0.37$ & 0.926 \\
\hline Length of intubation, (hours) ${ }^{\star *}$ & $8(3.5-15)$ & $5(1-16)$ & 0.152 \\
\hline Length of PICU stay, (days) ${ }^{\star \star}$ & $3(2-6)$ & $2(1-6)$ & 0.025 \\
\hline Length of hospitalization, (days)* & $11.45 \pm 1.51$ & $10.52 \pm 1.83$ & 0.147 \\
\hline
\end{tabular}

${ }^{*}$ mean $\pm S D$; ** median (min-max).

Student's $t$ test. Mann-Whitney U test. Pearson Chi-square test. Fisher's Exact Test. NA: Not applied. 
Of note, the present study found a limited effect of TXA on hemodynamics. Instead of a direct postoperative effect (due to the drug's half-life lasting 2 hours) $(6,10,13)$, TXA indirectly acted upon the hemodynamics by reducing intraoperative blood loss and transfusion volume. The ROC curve analysis indicated that $10.13 \mathrm{ml} / \mathrm{kg}$ (AUC: $0.885,95 \% \mathrm{Cl}=0.761-1.0$; sensitivity: $91 \%$, specificity: $80 \%$ ) of the pRBC transfusion during the procedure predicted the odds of hemodynamic changes by 3.033 times (OR: 3.033, 95\% Cl: 1.286-7.154; $p=0.011)$. However, the cutoff point in the present study was far behind the limits of Goobie et al. (11). They documented intraoperative blood transfusion of $>60 \mathrm{ml} / \mathrm{kg}$ as an independent risk factor for postoperative cardiorespiratory events. They created an algorithm to identify patients at risk for postoperative complications, but the transfusion volume in their study was above the limits of massive transfusion criteria in children $(>40 \mathrm{ml} / \mathrm{kg}$ ) (26). There is no doubt of the high probability of a postoperative event occurring for those receiving a massive transfusion; but the primary goal of therapy is to identify infants at risk before reaching the limit for a massive transfusion requirement. In cases of excessive intraoperative transfusion volumes, extending drug administration beyond the postoperative period might be an option to prevent hemodynamic and hematological events. Nevertheless, both clinical and pharmacokinetic studies are needed to investigate the precise dosing and the length of postoperative drug utilization for safer therapeutic management.

Documented drug-related adverse effects are scarce (21), even if doses reach the limits of recommendations (ranging from $10-100 \mathrm{mg} / \mathrm{kg}$ loading dose followed by $5-10 \mathrm{mg} /$ $\mathrm{kg} /$ hour maintenance infusion) $(9,13,19,22)$. The Pediatric Craniofacial Surgery Perioperative Registry database review announced a seizure rate of $0.6 \%$ in 1,638 children undergoing cranial vault surgery between 2010 and 2015; the outcomes were insignificant for children regardless of whether they received an intraoperative antifibrinolytic drug (8). The seizure rate was $0.3 \%$ (in 2/591 children) in a large multi-institutional study. It appears that seizures do not occur even at a loading dose of $100 \mathrm{mg} / \mathrm{kg}(13,24)$. We observed seizures in two and a superficial hematoma in four children. The search for the underlying causes of the seizures was inconclusive because both children had a history for epilepsy and had received antiseizure medication before the surgery. No thromboembolic events were observed in the study population. Despite the side effects that are reported in pediatric cardiac surgeries (23), further studies are needed to highlight the complications of antifibrinolytic drugs during craniosynostosis surgery.

We should also emphasize the necessity of close monitoring for those undergoing such an extensive procedure. The metabolic demands of small children are greater than those of any other age category. Not only postoperative blood loss but also the loss of interstitial fluid from the incision site could change the hemodynamic and metabolic demands. Restoring the metabolic balance $(\mathrm{pH}>7.35)$ within 6 hours after the procedure might be more than we could anticipate, due to the relatively large head circumference to body surface area.
The limitations of this study were the retrospective nature of the study and the relatively small study population. The inability to measure drug blood levels also prevented us from assessing the pharmacokinetics of TXA and TXA-related complications. The main strength was that we recorded all intraoperative and postoperative variables, including the assessment of cranial imaging.

\section{CONCLUSION}

Administering intraoperative TXA is crucial for successful management during the surgery; but the postoperative period is of paramount importance due to excessive bleeding (3). Postoperative utilization of TXA should be investigated in future studies to minimize the potential risks by balancing the pros and cons of the drug.

\section{REFERENCES}

1. Abrishami A, Chung F, Wong J: Topical application of antifibrinolytic drugs for on-pump cardiac surgery: A systematic review and meta-analysis. Can J Anesth 56(3):202212, 2009

2. Carver E, Marcus R, Tatman AF: FFP use in craniofacial surgery. Paediatr Anaesth 20(5):471, 2010

3. Chung E, Karlberg HI: Ulnar artery thrombosis following tranexamic acid administration for craniosynostosis repair. $\mathrm{J}$ Craniofac Surg 30(1):186-187, 2019

4. Crantford JC, Wood BC, Claiborne JR, Ririe DG, Couture DE, Thompson JT, David LR: Evaluating the safety and efficacy of tranexamic acid administration in pediatric cranial vault reconstruction. J Craniofac Surg 26(1):104-107, 2015

5. Czerwinski M, Hopper RA, Gruss J, Fearon JA: Major morbidity and mortality rates in craniofacial surgery: An analysis of 8101 major procedures. Plast Reconstr Surg 126(1):181-186, 2010

6. Dowd NP, Karski JM, Cheng DC, Carroll JA, Lin Y, James RL, Butterworth J: Pharmacokinetics of tranexamic acid during cardiopulmonary bypass. Anesthesiology 97(2):390-399, 2002

7. Durán de la Fuente P, García Fernández J, Pérez López C, Carceller F, Gilsanz Rodríguez F: Usefulness of tranexamic acid in cranial remodeling surgery. Rev Esp Anestesiol Reanim 50(8):388-394, 2003

8. Goobie SM, Cladis FP, Glover CD, Huang H, Reddy SK, Fernandez AM, Zurakowski D, Stricker PA, Gries H; The Pediatric Craniofacial Collaborative Group: Safety of antifibrinolytics in cranial vault reconstructive surgery: A report from the pediatric craniofacial collaborative group. Paediatr Anaesth 27(3):271-281, 2017

9. Goobie SM, Meier PM, Pereira LM, McGowan FX, Prescilla RP, Scharp LA, Rogers GF, Proctor MR, Meara JG, Soriano SG, Zurakowski D, Sethna NF: Efficacy of tranexamic acid in pediatric craniosynostosis surgery: A double-blind, placebocontrolled trial. Anesthesiology 114(4):862-871, 2011

10. Goobie SM, Meier PM, Sethna NF, Soriano SG, Zurakowski D, Samant S, Pereira LM: Population pharmacokinetics of tranexamic acid in paediatric patients undergoing craniosynostosis surgery. Clin Pharmacokinet 52(4):267-276, 2013 
Ongun EA. et al: Tranexamic Acid in Craniosynostosis Surgery

11. Goobie SM, Zurakowski D, Proctor MR, Meara JG, Meier PM, Young VJ, Rogers GF: Predictors of clinically significant postoperative events after open craniosynostosis surgery. Anesthesiology 122(5):1021-1032, 2015

12. Hans P, Collin V, Bonhomme V, Damas F, Born JD, Lamy M: Evaluation of acute normovolemic hemodilution for surgical repair of craniosynostosis. J Neurosurg Anesthesiol 12(1):3336,2000

13. Hansen JK, Lydick AM, Wyatt MM, Andrews BT: Reducing postoperative bleeding after craniosynostosis repair utilizing a low-dose transexamic acid infusion protocol. J Craniofac Surg 28(5):1255-1259, 2017

14. Hughes C, Thomas K, Johnson D, Das S: Anesthesia for surgery related to craniosynostosis: A review. Part 2. Pediatr Anesth 23(1):22-27, 2013

15. Jimenez DF, Barone CM: Intraoperative autologous blood transfusion in the surgical correction of craniosynostosis. Neurosurgery 37(6):1075-1079, 1995

16. Kelley JP, Boville BM, Sterken DJ, Sanfilipo DJ, Fahrenkopf M, Kelpin J, Polley J, Mann R, Girotto JA: Pediatric blood management protocol in cranial vault surgery. J Craniofac Surg 2019 (Epub ahead of print)

17. Kim EJ, Kim YO, Shim KW, Ko BW, Lee JW, Koo BN: Effects of tranexamic acid based on its population pharmacokinetics in pediatric patients undergoing distraction osteogenesis for craniosynostosis: Rotational thromboelastometry (ROTEM ${ }^{\mathrm{TM}}$ ) analysis. Int J Med Sci 15(8):788-795, 2018

18. Krajewski K, Ashley RK, Pung N, Wald S, Lazareff J, Kawamoto HK, Bradley JP: Successful blood conservation during craniosynostotic correction with dual therapy using procrit and cell saver. J Craniofac Surg 19(1):101-105, 2008

19. Kurnik NM, Pflibsen LR, Bristol RE, Singh DJ: Tranexamic acid reduces blood loss in craniosynostosis surgery. J Craniofac Surg 28(5):1325-1329, 2017

20. Longatti PL, Paccagnella F, Agostini S, Nieri A, Carteri A: Autologous hemodonation in the corrective surgery of craniostenosis. Childs Nerv Syst 7(1):40-44, 1991

21. Lu VM, Goyal A, Daniels DJ: Tranexamic acid decreases blood transfusion burden in open craniosynostosis surgery without operative compromise. J Craniofac Surg 30(1):120-126, 2019

22. Martin DT, Gries H, Esmonde N, Diggs B, Koh J, Selden NR, Schreiber M, Kuang AA: Implementation of a tranexamic acid protocol to reduce blood loss during cranial vault remodeling for craniosynostosis. J Craniofac Surg 27(6):15271531,2016

23. Martin K, Knorr J, Breuer T, Gertler R, Macguill M, Lange R, Tassani P, Wiesner G: Seizures after open heart surgery: Comparison of epsilon-aminocaproic acid and tranexamic acid. J Cardiothorac Vasc Anesth 25(1):20-25, 2011
24. Maugans TA, Martin D, Taylor J, Salisbury S, Istaphanous G: Comparative analysis of tranexamic acid use in minimally invasive versus open craniosynostosis procedures. J Craniofac Surg 22(5):1772-1778, 2011

25. Meneghini L, Zadra N, Aneloni V, Metrangolo S, Faggin R, Giusti F: Erythropoietin therapy and acute preoperative normovolaemic haemodilution in infants undergoing craniosynostosis surgery. Paediatr Anaesth 13(5):392-396, 2003

26. Neff LP, Cannon JW, Morrison JJ, Edwards MJ, Spinella PC, Borgman MA: Clearly defining pediatric massive transfusion: Cutting throug the fog and friction with combat data. J Trauma Acute Care Surg 78(1):22-28, 2015

27. Neilipovitz DT: Tranexamic acid for major spinal surgery. Eur Spine J 13 Suppl 1:S62-S65, 2004

28. Ngaage DL, Bland JM: Lessons from aprotinin: Is the routine use and inconsistent dosing of tranexamic acid prudent? Meta-analysis of randomised and large matched observational studies. Eur J Cardio-Thorac 37(6):1375-1383, 2010

29. Pietrini D: Intraoperative management of blood loss during craniosynostosis surgery. Paediatr Anaesth 23(3):278-280, 2013

30. Practice guidelines for perioperative blood management: An updated report by the American Society of Anesthesiologists Task Force on Perioperative Blood Management. Anesthesiology 122(2):241-275, 2015

31. Roback JD, Caldwell S, Carson J, Roback JD, Caldwell S, Carson J, Davenport R, Drew MJ, Eder A, Fung M, Hamilton M, Hess JR, Luban N, Perkins JG, Sachais BS, Shander A, Silverman T, Snyder E, Tormey C, Waters J, Djulbegovic B; American Association for the Study of Liver; American Academy of Pediatrics; United States Army; American Society of Anesthesiology; American Society of Hematology: Evidence-based practice guidelines for plasma transfusion. Transfusion 50(6):1227-1239, 2010

32. Song G, Yang P, Zhu S, Luo E, Feng G, Hu J, Li J, Li Y: Tranexamic Acid reducing blood transfusion in children undergoing craniosynostosissurgery. J Craniofac Surg 24(1):299-303, 2013

33. Vamvakas EC: Long-term survival rate of pediatric patients after blood transfusion. Transfusion 48(11):2478-2480, 2008

34. Vega RA, Lyon C, Kierce JF, Tye GW, Ritter AM, Rhodes JL: Minimizing transfusion requirements for children undergoing craniosynostosis repair: The $\mathrm{CHoR}$ protocol. J Neurosurg Pediatr 14(2):190-195,2014 